\title{
ARTIGOS
}

\section{Caracterização morfo-fisiológica e patogenicidade de Colletotrichum gloeosporioides da pupunheira}

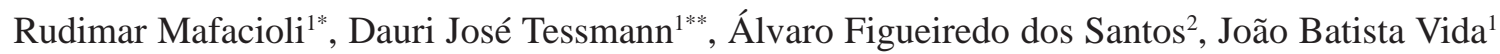

${ }^{1}$ Universidade Estadual de Maringá, Departamento de Agronomia, 87020-900, Maringá, PR; ${ }^{2}$ Embrapa Florestas, Estrada da Ribeira Km 111, 83411-000, Colombo, PR, bolsista do CNPq.

* Parte da Dissertação de Mestrado do primeiro autor, Universidade Estadual de Maringá.

**Autor para correspondência

Data de chegada: 22/09/2004. Aceito para publicação em: 12/07/2005.

\section{ABSTRACT}

Mafacioli, R.; Tessmann, D. J.; Santos, A. F.; Vida, J. B. Characterization morpho-physiological and pathogenicity of Colletotrichum gloeosporioides from peach palm. Summa Phytopathologica, v.32, n.2, p. 113-117, 2006.

Isolates of Colletotrichum sp. obtained from leaves of peach palm (Bactris gasipaes) showing symptoms of anthracnosis from several regions of Brazil were characterized and identified based on their phenotypic traits. A total of 17 isolates collected from the states of Acre and Rondônia, where the peach palm is originated as well as from Southern States such as Espirito Santo, São Paulo and Paraná, where peach palm has been introduced for the production of palm heart, were studied. Disease symptoms were characterized and the isolates were compared based on form and size of conidia and apressoria, color of the colony, mycelial growth and sporulation in vitro. The pathogenicity of all isolates was confirmed based on a detached leaf of peach palm assay. All isolates were characterized as Colletotrichum gloeosporioides and the occurrence of the meiosporic stage (Glomerella cingulata) was observed only for one isolate.

Additional key words: Anthracnosis, Bactris gasipaes, Glomerella cingulata.

\section{RESUMO}

Mafacioli, R.; Tessmann, D. J.; Santos, A. F.; Vida, J. B. Caracterização morfo-fisiológica e patogenicidade de Colletotrichum gloeosporioides da pupunheira. Summa Phytopathologica, v.32, n.2, p. 113-117, 2006.

Isolados de Colletotorichum sp. de folhas de pupunheira (Bactris gasipaes) com sintomas de antracnose foram comparados fenotipicamente, visando a sua caracterização e identificação. Foram analisados 17 isolados, oriundos dos Estados do Acre, Rondônia, Espírito Santo, São Paulo e Paraná. Caracterizaram-se os sintomas da doença e os isolados foram comparados em relação à forma e tamanho de conídios e apressórios, e quanto a coloração das colônias, crescimento micelial e esporulação em meio de cultura. A patogenicidade dos isolados foi confirmada em folhas de pupunheira destacadas. Todos os isolados foram identificados como Colletotrichum gloeosporioides e a fase meiospórica in vitro (Glomerella cingulata) ocorreu apenas em um isolado procedente de Linhares, Espírito Santo.

Palavras-chave adicionais: Antracnose, Bactris gasipaes, Glomerella cingulata.

A antracnose é a principal doença da pupunheira (Bactris gasipaes Kunth), causando danos principalmente em mudas e em plantios com até 6 a 8 meses de idade (8). A antracnose afeta principamente folhas de plantas jovens, caracterizando-se por manchas arredondadas e deprimidas, de coloração marrom, com anéis concêntricos. Além disso, essas lesões servem como porta de entrada para patógenos secundários e, com isso, agravam o quadro sintomatológico da doença.

$\mathrm{Na}$ América Central, a doença tem sido associada a Colletotrichum sp. (13) e no Brasil, embora não existam relatos de estudos mais aprofundados dessa associação, a espécie Colletotrichum gloeosporioides (Penz.) Sacc. é descrita como o agen- 
te causal da doença $(1,6,8)$. Em decorrência da expansão do cultivo da pupunheira para a produção de palmito no Brasil aumentou a importância da antracnose e de conhecimentos mais aprofundados da etiologia dessa doença. Nesse sentido, o objetivo do trabalho foi analisar a variabilidade em algumas características morfológicas e fisiológicas, bem como identificar a espécie de isolados de Colletotrichum sp. de folhas de pupunheira com sintomas de antracnose oriundas de diversas regiões do Brasil.

\section{MATERIAL E MÉTODOS}

\section{Obtenção dos isolados}

Os isolados foram obtidos de folhas da pupunheira com sintomas típicos de antracnose procedentes de várias regiões do Brasil (Tabela 1). Para a obtenção de culturas puras, utilizouse o método indireto, no qual fragmentos de tecido foliar doente, após desinfestação superficial, foram transferidos para placas contendo meio de batata-dextrose-ágar suplementado com ampicilina $(250 \mu \mathrm{g} / \mathrm{ml})(\mathrm{BDA}-\mathrm{S})$. As placas foram incubadas por cinco dias, a $25 \pm 2{ }^{\circ} \mathrm{C}$, sob fotoperíodo $12 \mathrm{~h} \mathrm{luz} / 12 \mathrm{~h}$ escuro. Após, retirou-se um disco de micélio da extremidade da colônia característica de Colletotrichum, transferindo-o para tubo de ensaio contendo meio BDA-S. Para todos os isolados, obtiveram-se culturas puras a partir de pontas de hifas. Os isolados foram mantidos em tubos de ensaio com meio de cultura BDA$\mathrm{S}$ e armazenados a $10^{\circ} \mathrm{C}$ ou em óleo mineral.

Tabela 1. Isolados de Colletotrichum gloeosporioides utilizados no estudo.

\begin{tabular}{lcc}
\hline Designação & Origem & $\begin{array}{c}\text { Data da coleta } \\
\text { (mês/ano) }\end{array}$ \\
\hline CGA-PR & Cidade Gaúcha (PR) & $12 / 2001$ \\
REG-SP1 & Registro (SP) & $02 / 2002$ \\
REG-SP2 & Registro (SP) & $02 / 2002$ \\
STO-PR1 & São Tomé (PR) & $02 / 2002$ \\
STO-PR2 & São Tomé (PR) & $02 / 2002$ \\
STO-PR3 & São Tomé (PR) & $02 / 2002$ \\
PGA-PR1 & Paranaguá (PR) & $02 / 2002$ \\
PGA-PR2 & Paranaguá (PR) & $02 / 2002$ \\
PGA-PR3 & Paranaguá(PR) & $02 / 2002$ \\
PGA-PR4 & Paranaguá (PR) & $02 / 2002$ \\
LIN-ES1 & Linhares (ES) & $02 / 2002$ \\
LIN-ES2 & Linhares (ES) & $02 / 2002$ \\
RBR-AC1 & Rio Branco (AC) & $03 / 2002$ \\
RBR-AC2 & Rio Branco (AC) & $03 / 2002$ \\
PVE-RO1 & Porto Velho (RO) & $03 / 2002$ \\
PVE-RO2 & Porto Velho (RO) & $03 / 2002$ \\
PVE-RO3 & Porto Velho (RO) & $03 / 2002$ \\
\hline
\end{tabular}

\section{Características culturais}

Para a análise do crescimento micelial, esporulação e coloração das colônias, os isolados foram crescidos em meio de cultura aveia-ágar (60 g de farinha de aveia, $12 \mathrm{~g}$ de ágar, 1000 $\mathrm{mL}$ de água destilada esterilizada), com incubação a $25 \pm 2{ }^{\circ} \mathrm{C}$, sob fotoperíodo de 12 horas, por cinco dias.

A avaliação do crescimento micelial consistiu na medição diária das colônias em dois sentidos diametralmente opostos, obtendo-se uma média para cada repetição. $\mathrm{O}$ delineamento estatístico do ensaio foi inteiramente casualizado, com três repetições, e empregou-se para comparação das médias o teste de Tukey, a $5 \%$ de probabilidade. Os dados foram analisados com programa SAEG (7).

As características culturais foram avaliadas com base no aspecto geral das colônias (contorno e cor do micélio) e na esporulação dos isolados, sendo a mesma descrita com base na distribuição das massas de conídios na placa, como abundante $(++)$, escassa (+) e ausente (-). Os isolados foram cultivados em meio BDA-S sob temperatura de $25 \pm 2{ }^{\circ} \mathrm{C}$ por 30 dias, para verificar a presença da fase sexuada.

Em todos os experimentos realizados, os dados obtidos foram submetidos à análise de variância e as médias comparadas pelo teste de Tukey $(\mathrm{P}=0,05)$.

\section{Caracterização dos sintomas e identificação do patógeno}

Folhas de pupunheira com sintomas de antracnose, procedentes de diversas regiões do País, foram analisadas no Laboratório de Fitopatologia da Universidade Estadual de Maringá. O material foi incubado em câmara úmida por 24 horas e em seguida prepararam-se lâminas com cortes finos de tecido necrosado para observação de acérvulos em microscópio ótico. A análise da morfologia de conídios e apressórios dos isolados baseou-se em culturas puras. Para isso, prepararam-se lâminas de microscópio com conídios em lactofenol e azul de algodão, as quais foram analisadas em microscópio óptico sob aumento de 100 X. Foram analisados 150 conídios para cada isolado em relação ao seu comprimento, largura e formato. Para a indução de formação de apressórios, colocou-se uma lâmina de microcópio no interior de uma placa de Petri e, em seguida, colocouse uma gota de $10 \mu \mathrm{L}$ de uma suspensão de conídios na concentração de 1 x $10^{5}$ conídios.mL-1 sobre a lâmina. Este material foi colocado em uma incubadora por 24 horas, a $25^{\circ} \mathrm{C}$, no escuro. A seguir, as lâminas foram retiradas, secas com papel absorvente (papel toalha) e uma gota de lactofenol com azul de algodão foi depositada sobre a lâmina. As observações foram realizadas em microscópio óptico, com ocular micrométrica, aumento de $100 \mathrm{X}$. Observou-se a morfologia e determinou-se o comprimento e a largura de 60 apressórios. Procedeu-se a comparação dos parâmetros morfométricos do patógeno com aqueles descritos por Sutton $(9,10)$.

\section{Teste de patogenicidade}

A doença foi reproduzida pela inoculação de folhas destacadas de mudas de pupunheira acondicionadas em placas de Petri, sobre duas camadas de papel filtro esterilizado. A inoculação foi realizada em ferimentos feitos com um conjunto de seis agulhas espaçadas de $5 \mathrm{~mm}$ e afixadas em rolha de cortiça, previamente flambadas. Em seguida, um disco de papel filtro de 10 mm de diâmetro, previamente embebido em uma suspensão conidial na concentração de $10^{5}$ conídios.mL-1, foi depositado 
sobre cada ponto da folha com ferimentos. Na testemunha, utilizou-se um disco de papel filtro embebido somente em água destilada sobre os ferimentos. As placas foram mantidas fechadas em incubadora tipo BOD a $22 \pm 2{ }^{\circ} \mathrm{C}$ e fotoperíodo de 12 horas por 10 dias. $\mathrm{O}$ delineamento do ensaio foi completo causalizado, com três repetições.

\section{RESULTADOS E DISCUSSÃO}

\section{Características culturais}

Foram observados quatro tipos de colônias, com a coloração variando de cinza-escuro a cinza-claro, branco e brancoacinzentado (Tabela 2). Os isolados apresentaram variações entre si na taxa de crescimento micelial, sendo que o isolado PGA-PR1, aos sete dias, já havia atingido a margem da placa, enquanto que, os isolados STO-PR1 e PVE-RO3 foram os de crescimento mais lento (Tabela 2). Todos os isolados produziram conídios no meio de cultura aveia-ágar, e a maioria produziu conídios em abundância (Tabela 2). A ocorrência de variabilidade na coloração de colônias, na esporulação e no crescimento micelial de C. gloeosporioides também foi verificada em isolados de cacaueiro (2), mangueira (4), cajueiro (5) e moranguei-

Tabela 2. Características culturais de isolados de Colletotrichum gloeosporioides da pupunheira em meio aveia ágar à temperatura de $25 \pm 2{ }^{\circ} \mathrm{C}$, após sete dias de incubação.

\begin{tabular}{|c|c|c|c|}
\hline Isolado & $\begin{array}{l}\text { Coloração } \\
\text { da colônia }\end{array}$ & $\begin{array}{c}\text { Crescimento } \\
\text { micelial }\left(\mathrm{mm}^{-1{ }^{-1}}{ }^{1}\right)^{1}\end{array}$ & Esporulação² \\
\hline CGA-PR & branca acinzentada & $8,3 \mathrm{ab}$ & $* *$ \\
\hline REG-SP1 & cinza clara & $7,7 \mathrm{bc}$ & $* *$ \\
\hline REG-SP2 & cinza escura & $7,7 \mathrm{bc}$ & $* *$ \\
\hline STO-PR1 & branca acinzentada & $6,8 \mathrm{bc}$ & $* *$ \\
\hline STO-PR2 & branca acinzentada & $7,8 \mathrm{abc}$ & $* *$ \\
\hline STO-PR3 & branca & $8,7 \mathrm{ab}$ & $* *$ \\
\hline PGA-PR1 & branca & $10,0 \mathrm{a}$ & $* *$ \\
\hline PGA-PR2 & branca acinzentada & $9,0 \mathrm{ab}$ & $* *$ \\
\hline PGA-PR3 & branca & $8,6 \mathrm{ab}$ & $* *$ \\
\hline PGA-PR4 & branca acinzentada & $8,8 \mathrm{ab}$ & $* *$ \\
\hline LIN-ES1 & branca & $7,2 \mathrm{bc}$ & $* *$ \\
\hline LIN-ES2 & branca acinzentada & $8,7 \mathrm{ab}$ & $* *$ \\
\hline RBR-AC1 & branca & $7,0 \mathrm{bc}$ & $* *$ \\
\hline RBR-AC2 & branca acinzentada & $8,4 \mathrm{ab}$ & $* *$ \\
\hline PVE-RO1 & branca acinzentada & $7,6 \mathrm{bc}$ & $* *$ \\
\hline PVE-RO2 & branca & $8,4 \mathrm{ab}$ & $*$ \\
\hline PVE-RO3 & branca & $6,1 \mathrm{c}$ & $*$ \\
\hline
\end{tabular}

${ }^{1}$ Médias seguidas da mesma letra não diferem entre si pelo teste de Tukey a 5\% de probabilidade; ${ }^{2}$ Esporulação abundante $(* *)$ e escassa (*). ro (11). O meio de aveia-ágar mostrou-se adequado para a obtenção de conídios de C. gloeosporioides da pupunheira, da mesma forma como Veras et al. (14) verificaram que este meio foi o melhor substrato para a produção de conídios de $C$. guaranicola.

Caracterização dos sintomas e identificação dos isolados

A análise das amostras de folhas de pupunheira com antracnose, procedentes de diversas regiões do Brasil, mostrou que a doença caracteriza-se por manchas arredondadas e deprimidas, de coloração marrom, com anéis concêntricos de cor escura. As lesões mais velhas apresentam centro claro e, devido à necrose dos tecidos, podem apresentar perfurações (Figura 1A). Nas áreas necrosadas formam-se acérvulos do patógeno (Figura 1B), nos quais pode surgir setas. Para todos os isolados, foram observados acérvulos típicos de Colletotrichum no tecido vegetal lesionado. No teste de patogenicidade, os primeiros sintomas apareceram aos sete dias após a inoculação, com formação de acérvulos e conídios.

Os conídios, observados ao microcópio óptico, apresentaram-se hialinos e unicelulares. A forma dos conídios variou de bastonete, elíptico à claviforme, com ápice obtuso e a base arredondada, algumas vezes truncada (Figura 1C). O tamanho dos conídios variou de 10,0 - $(17,7)$ - 24,2 $\mu$ m para comprimento e $2,5-(3,7)-5,0 \mu \mathrm{m}$ para largura, observando-se variações entre os isolados (Tabela 3).

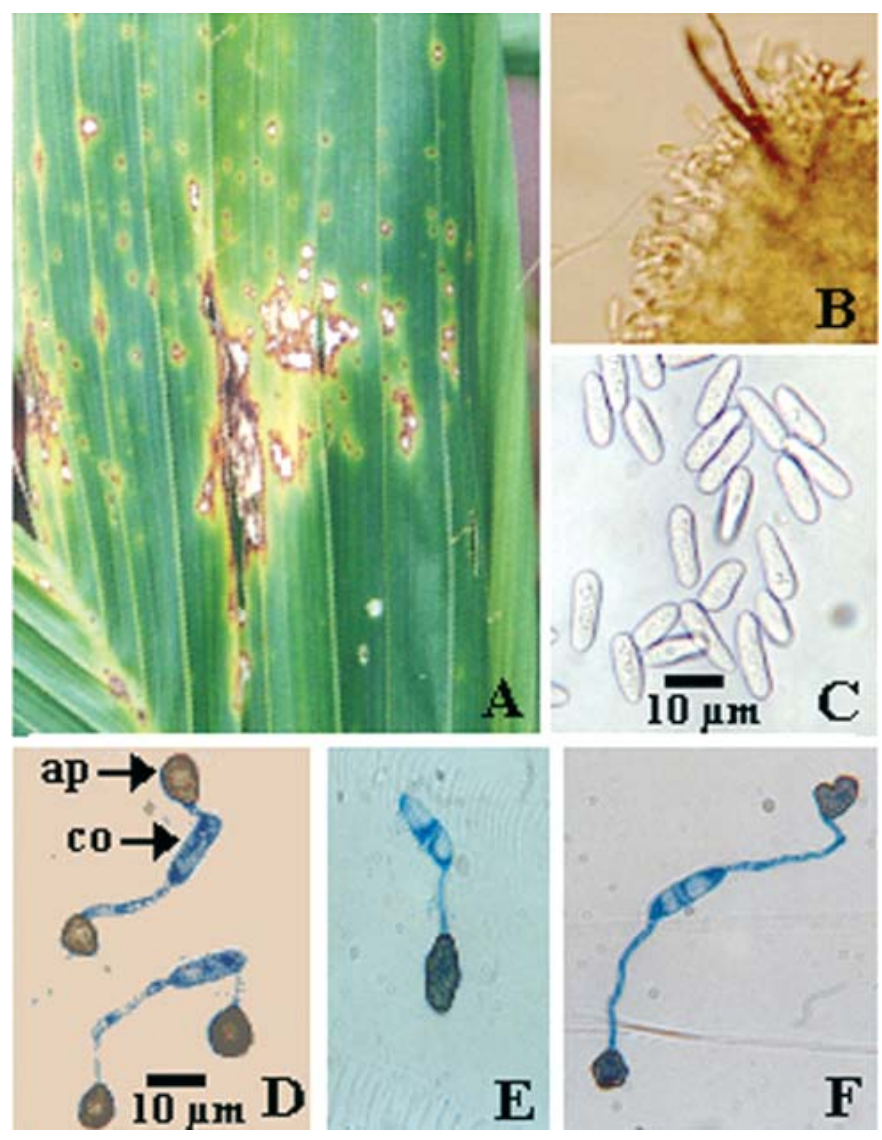

Figura 1. (A) Antracnose da pupunheira; Estruturas reprodutivas de Colletotrichum gloeosporioides: acérvulo (B); conídios (C); e conídios (co) com apressórios (ap) ovais (D), clavado (E) e irregulares (F). 
Os apressórios dos isolados apresentaram o formato clavado, irregular e oval; cor castanha com poro germinativo, localizado geralmente no centro (Figura 1D, 1E e 1F), com variações entre os isolados comparados (Tabela 3). As médias obtidas ficaram em 5,0 - (10,0) - 13,7 $\mu \mathrm{m}$ para comprimento e 3,7 - $(8,0)$ $-11,2 \mu \mathrm{m}$ para largura.

A morfologia dos conídios e de apressórios variou entre os isolados, porém ficou nos limites estabelecidos por Sutton (9, 10) para C. gloeosporioides. As características desta espécie de acordo com este autor são: colônias com coloração branca acinzentada a cinza escura, micélio aéreo uniforme, associado com conidiomata acervular, o reverso da cultura com coloração branca a cinza escura, especialmente em culturas mais velhas. As setas podem estar presentes ou ausentes. Escleródios ausentes. Apressórios com formato clavado, irregular ou oval, de cor marron-escura (castanha), medindo 6-20 x 4-12 mm. Conídios retos, lisos, cilíndricos, ápice obtuso, e algumas vezes com base truncada, medindo 12-17 (9-24) x 3.5-6 mm. Os conídios são formados em massa com aspecto mucilaginoso de coloração salmão

Verificou-se a ocorrência da fase meiospórica apenas para o isolado LIN-ES2, oriundo de Linhares, ES. Este isolado produziu peritécios, ascas e ascósporos, típicos da fase meiospórica Glomerella cingulata (3). Para os demais isolados não foi verificada a ocorrência da fase meiospórica durante o período de incubação das culturas. Não foi possível determinar porque isso ocorreu com apenas um isolado. Possivelmente, porque uma mesma espécie de Glomerella pode conter linhagens homotálicas e heterotálicas (12).

Tabela 3. Dimensões de conídios e apressórios, morfologia de apressórios e fase meiospórica de isolados de Colletotrichum gloeosporioides da pupunheira.

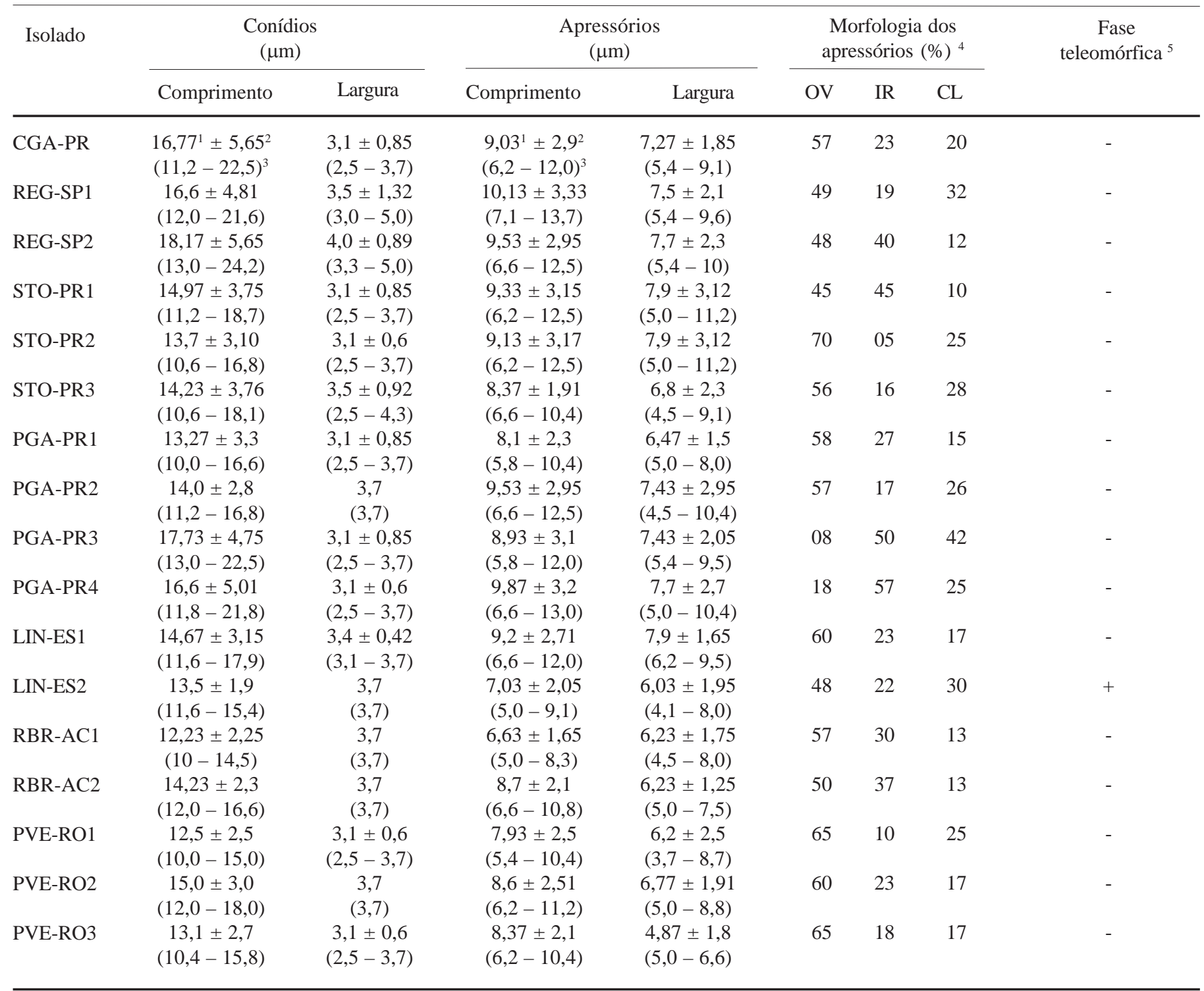

\footnotetext{
${ }^{1}$ Média de 150 conídios e 60 apressórios; ${ }^{2}$ Desvio padrão; ${ }^{3}$ Menor e maior tamanho; ${ }^{4} \mathrm{OV}=$ oval, $\mathrm{IR}=$ irregular; $\mathrm{CL}=\mathrm{clavado} ;{ }^{5}$ presença $(+)$ e ausência (-) após 30 dias de incubação em meio batata-dextrose-ágar à temperatura de $25 \pm 2{ }^{\circ} \mathrm{C}$.
} 


\section{REFERÊNCIAS BIBLIOGRÁFICAS}

1. Alves, M.L.B.; Batista, M.F. Ocorrência de antracnose em pupunha (Bactris gasipaes H.B.K.) em Manaus. Acta Amazônica, Manaus, v.13, n.3-4, p.705, 1983.

2. Feitosa, M.I.; Pimentel, C.P.V.; Oliveira, V.P.; Faria, B.; Chiba, S. Estudo comparativo de diversas culturas de Colletotrichum isoladas de cacaueiros (Theobroma cacao L.) no estado de São Paulo. Arquivos do Instituto Biológico, São Paulo, v.54, n.1/4, p.1725, 1987.

3. Hanlin, R.T. Illustrated Genera of Ascomycetes. St. Paul: APS Press, 1990. 263p.

4. Menezes, M.; Hanlin, R.T. Estudos comparativos sobres Colletotrichum gloeosporioides. II variações em isolados da antracnose da mangueira, em diferentes áreas do Nordeste Brasileira. Fitopatologia Brasileira, v.13 supl., p.110, 1988.

5. Menezes, M.; Hanlin, R.T. Estudos comparativos sobre Colletotrichum gloeosporioides. III, Variações em isolados da antracnose do cajueiro, em diferentes áreas do Nordeste do Brasil. Fitopatologia Brasileira, Brasília, v.13, supl., p.128, 1988.

6. Poltronieri, L.S.; Gasparoto, L.; Benchimol, R.L. Doenças da cultura da pupunheira. In: DUARTE, M.L.R. Doenças de plantas no trópico úmido Brasileiro. I. Plantas industriais. Belém: Embrapa,1999. p.209-217.

7. Ribeiro Jr., J.I. Análises Estatísticas no SAEG. Viçosa: Universidade Federal de Viçosa, 2001. 2001. 301p.
8. Santos, A.F.; Tessmann, D.J.; Nunes, W.M.C.; Vida, J.B.; Jaccoud Filho, D.S. Doenças foliares da pupunheira (Bactris gasipaes) no Estado do Paraná. Boletim de Pesquisa Florestal, Colombo, n.42, p.125-130, 2001b.

9. Sutton, B.C. The Coelomycetes, Kew: Commonwealth Mycological Institute, 1980. 696p.

10. Sutton, B.C. The genus Glomerella and its anamorph Colletotrichum, In: Bailey, J.A.; Jeger, M.J. Colletotrichum: biology, pathology and control, Wallingford: CAB International, 1992. cap.1, p.1-26.

11. Tanaka, M.A.S.; Passos, F.A. Caracterização cultural e morfofisiológica de isolados de Colletotrichum causadores de antracnose do morangueiro em São Paulo. Summa Phytopathologica, Campinas, v.24, n.2, p.145-151, 1998.

12. Vaillancourt, L.; Wang, J.; Hanau, R. Genetic regulation of sexual compatibility in Glomerella graminicola. In: Prusky, D.; Freeman, S.; Dickman, M.B. Colletotrichum: host specificity, pathology, and host-pothogen interaction. St. Paul: APS Press, 2000. cap. 3, p.29-44.

13. Vargas, E.; Vilaplana, M. Principales enfermedades del pejibaye observads em Costa Rica. Boletin Departamento de Investigaciones ASBANA, San José, v.3, n.7, p.8-9, 1979.

14. Veras, S.M.; Gasparotto, L.; Menezes, M. Variabilidade fisiomorfológica de Colletotrichum guaranicola em diferentes substratos. Arquivos de Biologia e Tecnologia, Curitiba, v.40, n.2, p.297-305, 1997. 